\title{
Spatially variable larval histories may shape recruitment rates of a temperate reef fish
}

\author{
Jeffrey S. Shima ${ }^{1, *}$, Stephen E. Swearer ${ }^{2}$ \\ ${ }^{1}$ School of Biological Sciences and Coastal Ecology Lab, Victoria University of Wellington, PO Box 600, Wellington, \\ New Zealand \\ ${ }^{2}$ Department of Zoology, University of Melbourne, Victoria 3010, Australia
}

\begin{abstract}
Several long-standing hypotheses purport variation in recruitment to be positively correlated with pelagic environmental conditions that enhance larval growth, survival, and/or delivery to recruitment sites. However, the relationship between recruitment intensity and larval environmental conditions (or more directly, larval condition) is difficult to evaluate and poorly known for most species. We evaluate this relationship for the reef fish Forsterygion lapillum that commonly inhabits rocky reefs throughout New Zealand. We quantified variation in recruitment of $F$. lapillum using a nested sampling design, and found that the largest source of variation was between 2 nearby regions (a semi-enclosed harbour and an adjacent open coast system). We estimated 'settler condition' as the composite of residual body mass and 2 measurements of larval growth (reconstructed from otolith microstructure) and found that recruitment intensity was positively correlated with settler condition for sites within the harbour, but negatively correlated with settler condition for sites on the open coast. Mean pelagic larval duration of recruits to the harbour was $\sim 3 \mathrm{~d}$ shorter than recruits to the open coast. These results suggest that larval experience and relationships between recruitment and settler condition are spatially variable. We speculate that (1) larval retention within a productive embayment facilitates a positive relationship between recruitment and settler condition while (2) dispersal through a less productive environment drives a negative relationship for replenishment on the open coast. These putative differences may have important implications for patterns of recruitment, the strength of post-settlement density-dependent interactions, and dynamics of local populations.
\end{abstract}

KEY WORDS: Recruitment variability $\cdot$ Settler condition $\cdot$ Larval history $\cdot$ Dispersal $\cdot$ Connectivity · Match-mismatch hypothesis · Ocean-stability hypothesis $\cdot$ Member-vagrant hypothesis $\cdot$ Reef fish

\section{INTRODUCTION}

Recruitment of marine organisms is notoriously variable (Caley et al. 1996). This variability is partially attributable to the complex life-histories of many marine organisms: spawners are capable of producing large numbers of larvae with highly variable fates, and these propagules have the potential for long-distance dispersal (Caley et al. 1996, Kritzer \& Sale 2004). Recruitment variability has fundamental implications for the dynamics of marine populations (Caley et al. 1996, Shima 1999), and greatly challenges the effective management of harvested species (Beverton \& Holt 1957).

Understanding sources of variation in recruitment of marine organisms has been a long-standing goal of marine ecologists, fisheries scientists and resource managers. Several fisheries-based hypotheses (e.g. 'Match-mismatch': Cushing 1975; 'Ocean stability': Lasker 1981; 'Member-vagrant': Sinclair 1988) purport variation in recruitment to be a function of pelagic environmental conditions, which may enhance growth, survival, and/or delivery of larvae to recruitment sites (see Leggett \& Frank 2008 for a recent review). Similarly, many ecological studies highlight important linkages between conditions experienced by larvae in more offshore environments and the magnitude of onshore recruitment strength (e.g. Gaines \& Roughgarden 1987, Wilson \& Meekan 2001, 2002, Bergenius et al. 2002, Lemberget \& McCormick 2009, Vallès et al. 2009).

Marine populations are increasingly studied as metapopulations (Swearer et al. 2002, Kritzer \& Sale 2004, Keough \& Swearer 2007), highlighting the role of 
spatial structure and connectivity among distinct local populations. Within this framework, local populations may be replenished by larvae from local (Jones et al. 1999, Swearer et al. 1999, 2002, Almany et al. 2007) and more distant source populations (Cowen et al. 2006). This spatial structure also implies that the larvae recruiting to different local populations may have experienced different developmental environments (Shima \& Swearer 2009), and consequently, that relationships between conditions in the larval environment and recruitment strength may be spatially or temporally variable (e.g. Vallès et al. 2009).

Environmental conditions often leave a 'signature' on organisms. Larvae that develop in favourable conditions may experience shorter larval durations, faster growth rates, and/or higher body condition indices (e.g. McCormick \& Molony 1995, Meekan et al. 2003, Phillips 2004). These sub-lethal effects of environmental variation on organisms enable us to evaluate relationships between recruitment intensity and individual 'condition', where the latter serves as a proxy for conditions in the pelagic larval environment, and the relationship between these 2 factors is likely to affect postsettlement processes.

Here, we explore patterns of recruitment variability in a common reef fish, across a range of spatial scales and through time. We estimate the 'condition' of recently settled fish (i.e. a composite of phenotypes, used here as a proxy for larval environment). We ask whether variation in larval environmental conditions (or more directly, settler condition) is capable of predicting variation in recruitment. Variation in the relationships between recruitment strength and recruit condition across different populations may reflect spatially structured variation in underlying processes that could have important implications for recruitment dynamics and the strength of density-dependent interactions in older age classes.

\section{MATERIALS AND METHODS}

Study system. We explored patterns and sources of variation in recruitment of the common triplefin Forsterygion lapillum. F. lapillum is a small reef fish that is common and abundant in shallow rocky reefs and in tide pools throughout New Zealand (Wellenreuther et al. 2007). Females spawn benthic egg clutches that are cared for by territorial males for $\sim 2$ wk until hatching (authors' unpubl. data). Larvae develop in the pelagic environment for $\sim 50 \mathrm{~d}$ (Shima \& Swearer 2009) before settling to fronds of macroalgae (McDermott \& Shima 2006).

We sampled recently settled Forsterygion lapillum from multiple sites within Wellington Harbour and the adjacent Wellington south coast, New Zealand. Wellington Harbour is a semi-enclosed embayment that receives substantial discharge from the Hutt River (average flow for $2004=3 \times 10^{6} \mathrm{~m}^{3}$ water $\mathrm{d}^{-1}$, peak flow $=$ $92 \times 10^{6} \mathrm{~m}^{3}$ water $\mathrm{d}^{-1}$ on 16 February 2004; Wellington Regional Council). Tidal exchange between the harbour and the open coast is limited (roughly $4.5 \%$ of the total harbour volume per tidal cycle, Maxwell 1956). Relative to the south coast (which abuts Cook Strait, separating the North and South Islands of New Zealand), Wellington Harbour is more typically a nutrient-enriched environment with greater concentrations of plankton (Gardner 2000). Over the period of our sampling, water temperature within the harbour was $16.74^{\circ} \mathrm{C}$ on average (range: 13.99 to 18.08 ) and $14.80^{\circ} \mathrm{C}$ (10.10 to 16.39) on the open coast.

Our previous work in this system (Shima \& Swearer 2009) used otolith microchemistry to infer heterogeneity in larval experiences and putative natal source populations that replenish the sites within the current study. Specifically, we found that all sites received recruits that originated from one of 2 distinct 'natal source syndromes', and similarly, one of 2 distinct 'dispersal history syndromes'. We (Shima \& Swearer 2009) speculated that these distinct syndromes corresponded to environmental signatures of natal origin and/or a larval developmental period within either the harbour or the open coast. The probable connections between these 2 distinct regions, and the environmental differences between them, motivate our present study.

Quantifying variation in recruitment. We used standardised larval collectors (i.e. artificial substrates comprised of plastic mesh bundles, described in Ammann 2004 and Shima \& Swearer 2009) to sample recently settled Forsterygion lapillum at approximately weekly intervals between December 2003 and March 2004 (spanning the period of peak recruitment for this species, authors' unpubl. data). We assume that our standardised collectors provide refuges for recently settled fishes that are homogeneous across sampling units, such that any effects of post-settlement processes are unlikely to bias our results (though we consider this possibility further in the 'Discussion'). Recruitment collectors were deployed on or near rocky reefs, attached to permanent mooring lines $2 \mathrm{~m}$ above the substrate, to simulate the canopies of macroalgae. Three collectors were deployed to each of the 6 sites within the Wellington region. Replicate collectors within each site were separated from one another by at least $20 \mathrm{~m}$. Three of the 6 sites (Kaiwharawhara, Eastbourne, and Shelly Bay) were located within the Wellington Harbour. The remaining 3 sites (Island Bay, Princess Bay, and Moa Point) were located along the adjacent Wellington south coast. All F. lapillum recruits were counted and cleared from each collector at each sam- 
pling event. Recruitment rates were estimated as the number of $F$. lapillum individuals standardised by the number of intervening days between sampling events, to yield an estimate of recruitment in units of recruits $\mathrm{d}^{-1}$ for each collector.

We designed and implemented a fully nested sampling design, and we analysed spatio-temporal variation in recruitment using nested-ANOVA (PROC GLM, SAS v9.1). On each of 8 dates (roughly weekly intervals), we sampled from 2 regions (harbour or south coast), at 3 sites within each region, and from 3 replicate collectors per site. Hence, our statistical model nests 'region' within 'date', and 'site' within 'region' and 'date', to explore patterns and sources of recruitment variability. We analysed a 4 th root transformation of recruitment rates because our data were strongly right-skewed. This transformation resulted in a response variable that conformed to assumptions of ANOVA. We used variance components calculated for each effect in our model to determine important sources of spatio-temporal variation in recruitment.

Quantifying settler condition. A subsample of 352 fish was used to characterise settler condition for each site and collection date (we randomly sampled $\sim 10$ ind. per site for each collection date, or all individuals if available samples were $<10$ ). We used residual body mass, instantaneous larval growth rate, and late larval growth to estimate a composite measure of 'settler condition'. We focused on these individual measures of larval phenotype because all 3 have been used in previous studies as proxies for larval condition (e.g. Searcy \& Sponaugle 2000, Shima \& Findlay 2002, Holmes \& McCormick 2009, Shima \& Swearer 2009). Residual body mass for each newly settled Forsterygion lapillum was estimated as the residual variance following a linear regression of wet weight on fish standard length using all 352 samples (we used a linear model because the relationship between length and weight appeared linear). Two complementary estimates of larval growth were reconstructed from analyses of daily growth increments recorded along the postrostral axis of sagittal otoliths. Otoliths were prepared following the methods of Shima \& Swearer (2009). We used an image analysis system consisting of a compound microscope, a digital camera, and computerbased image analysis software (Image Pro Plus v5.0) to measure the sequence of daily otolith increment widths from hatching to settlement for each fish (detailed in Shima \& Swearer 2009). We estimated 'late larval growth' as the average increment width across the final $5 \mathrm{~d}$ of larval growth prior to the settlement mark that was visible on each otolith. We estimated 'instantaneous larval growth rate' using a maximum likelihood approach (NLIN procedure, SAS v9.1) that fit an exponential model to the larval otolith growth trajectory of each fish (after Shima \& Findlay 2002):

$$
L_{t}=a \times \exp ^{b t}
$$

where $L_{t}$ is the otolith increment width $(\mu \mathrm{m})$ at time $t$ (d) in the larval stage, $a$ is the maximum-likelihood estimate of width at $t=0$, and $b$ is the maximum-likelihood estimate of instantaneous growth rate (i.e. a mea-

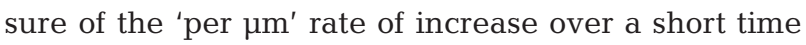
interval; units $=\mu \mathrm{m} \mu \mathrm{m}^{-1} \mathrm{~d}^{-1}$ ). We applied an exponential growth model to our data because we observed otolith growth patterns to be exponential in form.

We used a principal components analysis (PCA) to obtain a composite measure of 'settler condition' based upon residual body mass, instantaneous larval growth rate, and late larval growth.

Relationship between recruitment and settler condition. We used analysis of covariance (ANCOVA) (PROC GLM, SAS v9.1) to evaluate the relationship between recruitment intensity (4th root transformed, daily recruitment rate) and settler condition (the first principal component score, PC1 from the PCA). We evaluated this relationship as a function of 'region' (either harbour or south coast; treated as a fixed factor in our ANCOVA model) because (1) our analyses of recruitment variability (see 'Results') indicated this to be the most important source (i.e. scale) of variation in our dataset, and (2) we expected a priori that environmental conditions experienced by developing larvae would vary between regions (Shima \& Swearer 2009).

As the relationship between recruitment and settler condition may vary spatially due to differences in developmental history, we also evaluated spatio-temporal variation in pelagic larval duration (PLD) using 2-way ANOVA (PROC GLM, SAS v9.1). Collection date and region were each treated as fixed factors in this analysis.

\section{RESULTS}

Recruitment of Forsterygion lapillum varied spatially but not among sample dates in our study (Table 1, Fig. 1). Of the variation in recruitment intensity, $37 \%$ was partitioned to 'region' (harbour or south coast), while $35.5 \%$ was explained by sites within regions. Differences between collectors within sites accounted for the residual variance $(27.5 \%)$, and our analysis did not attribute any variance in recruitment intensity to sample date (Table 1). Recruitment intensity was generally greater at sites within Wellington Harbour, though one site on the south coast (Island Bay) received relatively high levels of recruitment of $F$. lapillum that were comparable to the harbour (Fig. 1).

A PCA revealed a high degree of colinearity between the 2 otolith-based metrics of larval quality (instantaneous larval growth vs. late larval growth, $\mathrm{r}=$ 
Table 1. Forsterygion lapillum. Variation in recruitment intensity of the common triplefin. Recruitment was sampled on 8 dates, and at 2 regions within each date. Three sites nested within each region were sampled with 3 replicate recruitment collectors (represented by the error term in a fully nested ANOVA model). Variance components are given for each effect, and collectively these suggest that recruitment variability has a large spatial component. See Fig. 3 for a summary of spatial variation in recruitment

\begin{tabular}{|lcccccc|}
\hline Source & df & SS & MS & $F$ & $p$ & $\begin{array}{c}\text { Variance } \\
\text { component }\end{array}$ \\
\hline Date & 7 & 2.89 & 0.41 & 0.40 & 0.88 & 0 \\
Region (Date) & 8 & 8.35 & 1.04 & 3.49 & 0.0053 & 37.06 \\
Site (Region [Date]) & 32 & 9.56 & 0.30 & 4.87 & $<0.0001$ & 35.47 \\
Error & 96 & 5.88 & 0.06 & & & 27.46 \\
\hline
\end{tabular}

tler condition' (e.g. individuals with high PC1 scores grew quickly and had larger residual weights at settlement relative to those with low PC1 scores).

Spatio-temporal variation in recruitment of Forsterygion lapillum was strongly correlated with settler condition, though the nature of this relationship differed between regions (Fig. 2). ANCOVA revealed a significant interaction between settler condition and region $\left(F_{1,39}=9.85, \mathrm{p}=0.0032\right)$. Within Wellington Harbour, recruitment of $F$. lapillum was positively correlated with settler condition $(r=0.47)$. For sites on

0.68). The relationship between settler condition and the 2 otolith-based traits was weaker, though still positive for both (residual body mass vs. instantaneous larval growth, $\mathrm{r}=0.16$; residual body mass vs. late larval growth, $r=0.24)$. The PC1 accounted for $60 \%$ of the overall variation in our dataset, and all 3 variables loaded positively onto this PC1 (PC1 loadings: residual body mass $=0.34$, instantaneous larval growth rate $=$ 0.66 , late larval growth $=0.67$ ). These loadings indicate that PC1 gives a reasonable composite measure of 'set- the Wellington south coast, however, the relationship between recruitment and settler condition was negative (Fig. 2, $\mathrm{r}=-0.44)$. Overall recruitment intensity differed between regions $\left(F_{1,39}=14.52, \mathrm{p}=0.0005\right)$. The effect of settler condition (alone) on recruitment intensity was not significant $\left(F_{1,39}=0.92, \mathrm{p}=0.34\right)$, due to the strong interaction with region.

PLD varied through time and was generally shortest in mid-summer when compared to early or late summer (Fig. 3a). The interaction between sampling date

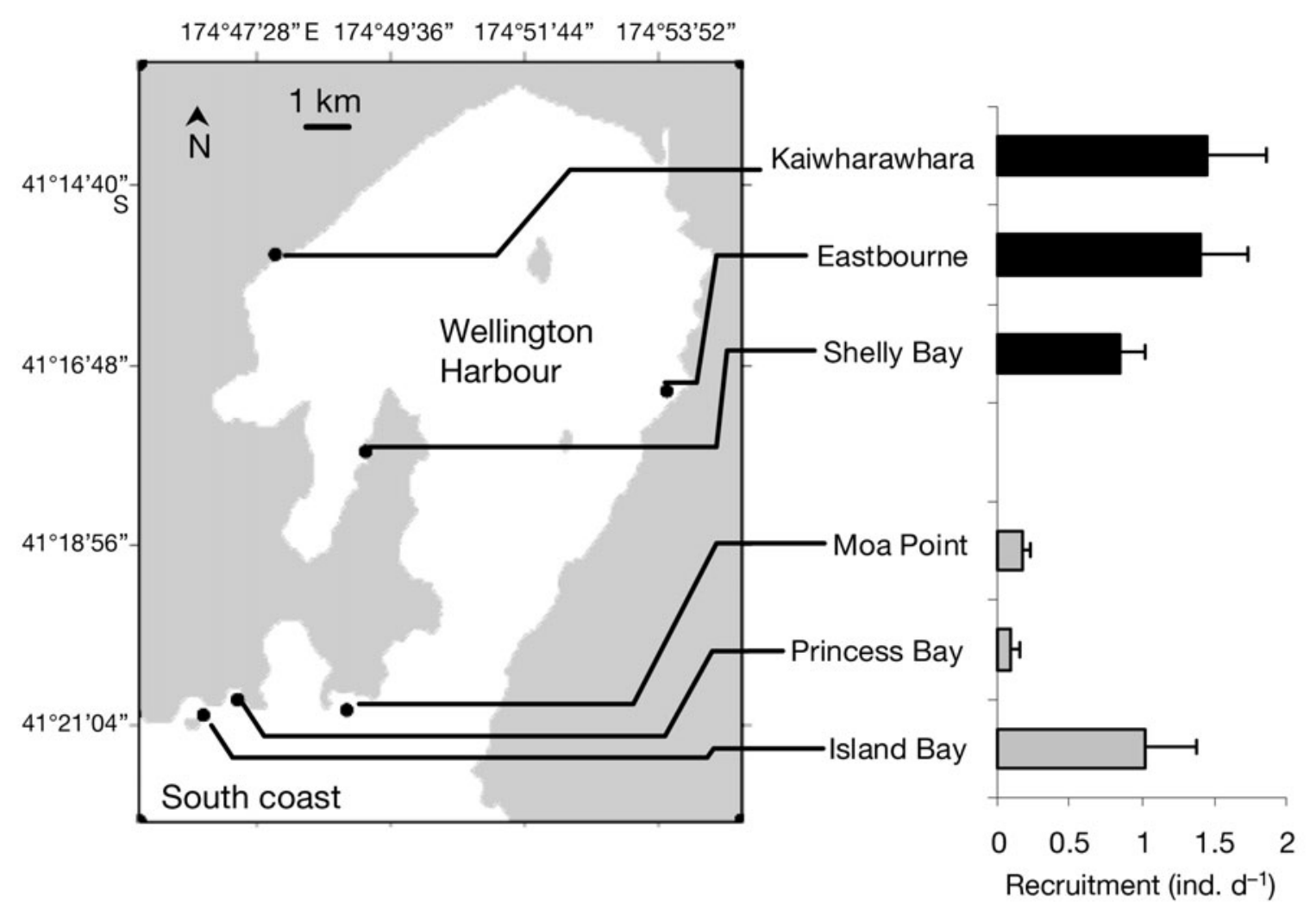

Fig. 1. Forsterygion lapillum. Spatial variation in recruitment of the common triplefin at 6 sites nested within 2 coastal regions (harbour or south coast) of Wellington, New Zealand. Locations of sites and time-averaged (+1 SE) daily recruitment rates per collector. See Table 1 for supporting statistics of nested-ANOVA 


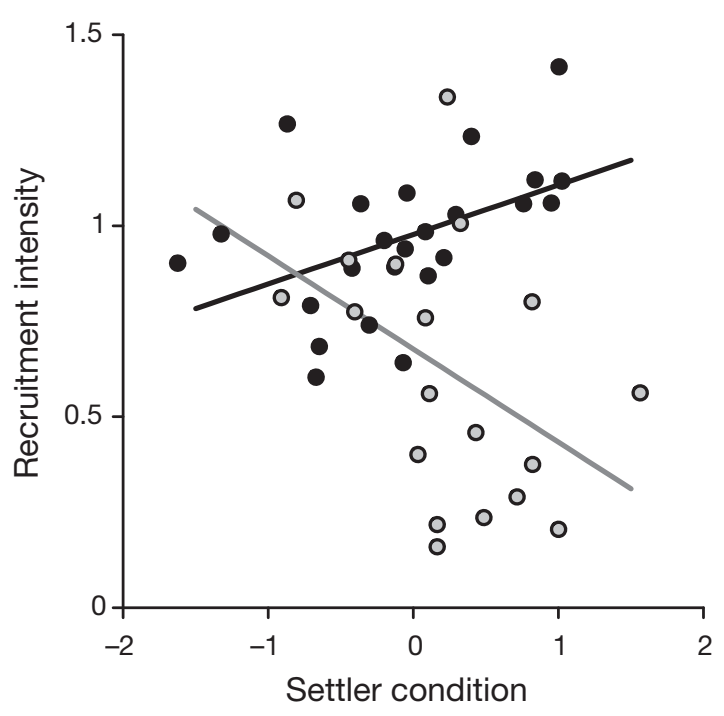

Fig. 2. Forsterygion lapillum. Settler condition predicts intensity of recruitment differently for harbour region (black dots and fitted line) and south coast region (grey dots and fitted line). Settler condition reflects a composite of instantaneous larval growth rate, late larval growth rate (both estimated from otolith microstructure), and residual (i.e. length-adjusted) body mass. Recruitment intensity is a 4th-root transformation of mean daily recruitment per collector, for a given site and date. Fitted lines reflect results of ANCOVA

and region was not significant in a 2-way ANOVA $\left(F_{7,336}=0.64, \mathrm{p}=0.73\right)$, indicating that the pattern of variation in PLD through time was generally consistent between regions. A reduced model that excluded the interaction term indicated that PLD varied among dates $\left(F_{7,343}=2.95, \mathrm{p}=0.005\right)$ and between region $\left(F_{1,343}=7.97, \mathrm{p}=0.005\right)$. PLD was significantly longer for fish recruiting to sites on the open coast (Fig. 3b). On average, fish collected from the harbour completed their larval development nearly $3 \mathrm{~d}$ faster than fish collected from the open coast.

\section{DISCUSSION}

Different processes appear to shape patterns of recruitment of Forsterygion lapillum within Wellington Harbour relative to the adjacent open coast. In the harbour, larval durations were comparatively short, fish recruitment was high, and the intensity of recruitment increased with settler condition. In contrast, along the open coast, larval durations were longer, rates of recruitment were lower, and the intensity of recruitment was negatively correlated with settler condition.

Wellington Harbour is a semi-enclosed basin with limited tidal exchange. Relative to the open coast, the harbour is comparatively sheltered, nutrient enriched,

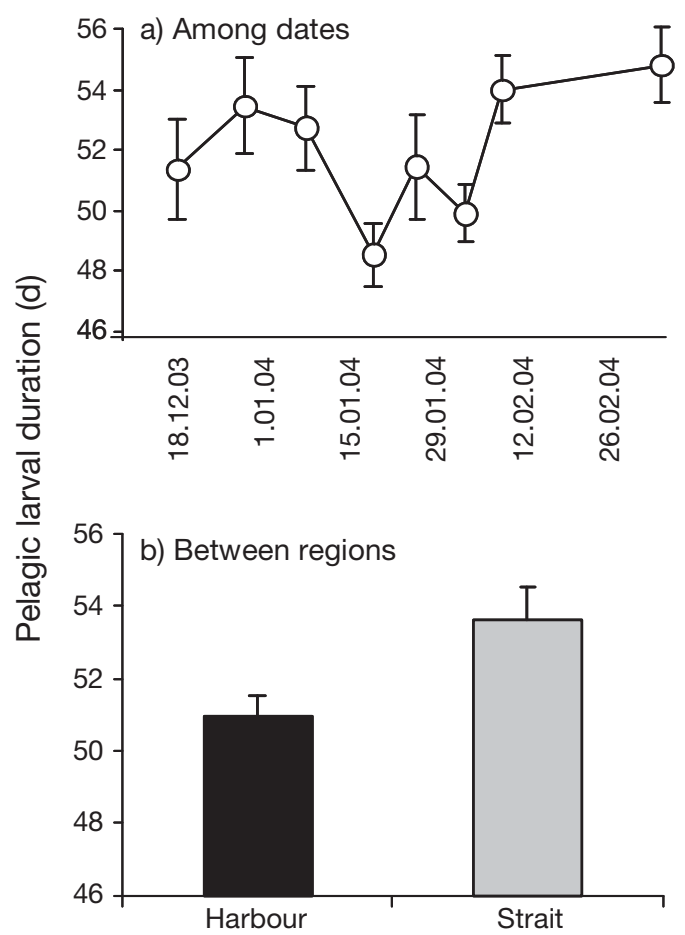

Fig. 3. Forsterygion lapillum. Variation in average development time (pelagic larval duration) (a) among dates (d/mo/yr) and (b) between regions (+1 SE)

warmer, supports higher standing stocks of planktonic biomass (Helson et al. 2007), and has a distinct benthic assemblage (McDermott 2005, Phillips \& Hutchison 2008). The adjacent open coast, in contrast, is flushed by the strong tidally driven currents of Cook Strait, and the notable absence of many benthic filter-feeding invertebrates (Gardner 2000) on rocky shores is suggestive of limited standing stocks of planktonic food resources in the nearshore coastal environment.

Overall, these patterns suggest that Wellington Harbour may be a developmentally favourable environment, in which nutrients, planktonic food resources, and larvae may be locally retained. The positive correlation between recruitment intensity and settler condition may arise here because the system is relatively closed: within this system, 'better' environmental conditions (manifested in the phenotypes of settlers) may result in increased rates of larval development, reduced probability of advection out of the harbour, and increased larval survival to recruitment-the net effect of these would result in a shorter PLD and a positive correlation between recruitment and condition. Though this hypothesis is largely speculative, it is intuitively appealing and consistent with other lines of evidence (Shima \& Swearer 2009) derived from otolith microchemistry, which suggest (1) the majority of recruits within Wellington Harbour originated from 
natal populations also within the harbour; and (2) larvae that developed within the harbour were of better quality, regardless of their natal origins.

The negative correlation between recruitment and settler condition on the open coast is more difficult to explain. However, given the strongly advective currents of Cook Strait, we hypothesise that recruitment of Forsterygion lapillum along the open coast may be comprised of a higher proportion of larvae that dispersed over longer distances and were supplied from different natal source populations or regions (including the likely possibility that larvae were flushed from the adjacent harbour; Shima \& Swearer 2009). Under this postulated scenario, recruitment along the open coast may be greatest when hydrodynamic conditions favour delivery of non-locally sourced recruits. We speculate that these recruits may arrive in poorer condition and en masse because they dispersed primarily through poorer quality (e.g. food depleted) environments, and/or because they represent the lower end of the likely distribution of 'settler condition' for fish that developed within the adjacent harbour, i.e. the individuals that are perhaps most susceptible to advection out of the harbour during flushing events.

We believe that our study emphasises spatial variability in pre-settlement processes that may shape recruitment strength for a reef fish. However, we cannot rule out the possibility that post-settlement processes (e.g. selective mortality on settlers with specific phenotypes, which may have occurred after settlement but prior to our collections) also contributed to the observed patterns. We know from other studies (authors' unpubl. data) that fish transplanted to our standardised settlement collectors experience selective mortality, though our data suggest that the pattern of selectivity is similar between sites in the harbour and on the open coast. Thus, we do not believe that the fundamentally different relationships between recruitment and settler condition for these 2 regions can be attributed to post-settlement processes.

Regardless of the underlying mechanisms responsible for these patterns, our results highlight substantial spatial variation in the relationship between recruitment strength and settler condition. Several studies have found recruitment strength to be correlated with larval food availability (e.g. Beaugrand et al. 2003, Castonguay et al. 2008), temperature (e.g. Wilson \& Meekan 2001, 2002, Baumann et al. 2006), or larval growth rates (e.g. Bergenius et al. 2002, Meekan et al. 2003, Jenkins \& King 2006). However, other studies have failed to find support for such relationships (e.g. Leggett \& DeBlois 1994, Sponaugle et al. 2006), and a recent study by Vallès et al. (2009) documents substantial variability in relationships between larval environmental features and recruitment across several species of coral reef fish.
Spatial variation may be inherent in the dispersal environments of most marine organisms, and our findings suggest that this variability has the potential to contribute to variation in recruitment. The patterns that we observed may indicate important effects of pre-settlement processes (e.g. higher settler condition may signal favourable developmental environments and higher larval survivorship within the harbour), and the relationships themselves may have further consequences for post-settlement processes. For example, the very different patterns of covariance between recruitment and settler condition that we observed indicate that large recruitment events (and higher recruit densities) within the harbour are associated with an influx of fish in good condition, whereas similar large recruitment events along the open coast may largely be comprised of fish in poorer condition. These differences may affect the strength of density-dependent interactions in the 2 regions (e.g. Shima \& Osenberg 2003), and local dynamics of reef fish populations well after settlement. Improved understanding of the relationships between recruitment strength and larval experiences, and their implications for post-settlement processes, may facilitate more effective management of fisheries and/or conservation of threatened marine resources.

Acknowledgements. This research was funded by 2 Marsden grants from the Royal Society of New Zealand (2003-04, to J.S.S. and S.E.S.; and 2007-09, to J.S.S., S.E.S., and S. Chiswell), and by supplementary funding from Victoria University of Wellington. Logistic support was provided by the Victoria University Coastal Ecology Lab (VUCEL), of which this paper is a contribution. We gratefully acknowledge the research and technical assistance from the following people: V. Hernaman, C. McDermott, M. Forsyth, S. Geange, B. Dudley, L. Liggins, J. Allen, R. Williamson, J. Long, D. McNaughtan, and J. Ford.

\section{LITERATURE CITED}

Almany GR, Berumen ML, Thorrold SR, Planes S, Jones GP (2007) Local replenishment of coral reef fish populations in a marine reserve. Science 316:742-744

Ammann AJ (2004) SMURFs: standard monitoring units for the recruitment of temperate reef fishes. J Exp Mar Biol Ecol 299:135-154

Baumann H, Hinrichsen HH, Mollmann C, Koster FW, Malzahn AM, Temming A (2006) Recruitment variability in Baltic Sea sprat (Sprattus sprattus) is tightly coupled to temperature and transport patterns affecting the larval and early juvenile stages. Can J Fish Aquat Sci 63: 2191-2201

> Beaugrand G, Brander KM, Lindley JA, Souissi S, Reid PC (2003) Plankton effect on cod recruitment in the North Sea. Nature 426:661-664

Bergenius MAJ, Meekan MG, Robertson DR, McCormick MI (2002) Larval growth predicts the recruitment success of a coral reef fish. Oecologia 131:521-525 
Beverton RJH, Holt SJ (1957) On the dynamics of exploited fish populations. Chapman \& Hall, London

Caley MJ, Carr MH, Hixon MA, Hughes TP, Jones GP, Menge BA (1996) Recruitment and the local dynamics of open marine populations. Annu Rev Ecol Syst 27:477-500

Castonguay M, Plourde S, Robert D, Runge JA, Fortier L (2008) Copepod production drives recruitment in a marine fish. Can J Fish Aquat Sci 65:1528-1531

Cowen RK, Paris CB, Srinivasan A (2006) Scaling of connectivity in marine populations. Science 311:522-527

Cushing DH (1975) Marine ecology and fisheries. Cambridge University Press, Cambridge

Gaines SD, Roughgarden J (1987) Fish in offshore kelp forests affect recruitment to intertidal barnacle populations. Science 235:479-481

> Gardner JPA (2000) Where are the mussels on Cook Strait (New Zealand) shores? Low seston quality as a possible factor limiting multi-species distributions. Mar Ecol Prog Ser 194:123-132

> Helson JG, Pledger S, Gardner JPA (2007) Does differential particulate food supply explain the presence of mussels in Wellington Harbour (New Zealand) and their absence on neighbouring Cook Strait shores? Estuar Coast Shelf Sci 72:223-234

> Holmes TH, McCormick MI (2009) Influence of prey body characteristics and performance on predator selection. Oecologia 159:401-413

Jenkins GP, King D (2006) Variation in larval growth can predict the recruitment of a temperate, seagrass-associated fish. Oecologia 147:641-649

Jones GP, Milicich MJ, Emslie MJ, Lunow C (1999) Selfrecruitment in a coral reef fish population. Nature 402: 802-804

Keough MJ, Swearer SE (2007) Early life histories of marine invertebrates and fishes. In: Connell SD, Gillanders BM (eds) Marine ecology. Oxford University Press, Oxford, p 19-46

Kritzer JP, Sale PF (2004) Metapopulation ecology in the sea: from Levins' model to marine ecology and fisheries science. Fish Fish 5:131-140

Lasker R (1981) Marine fish larvae: morphology,ecology, and relation to fisheries. University of Washington Press, Seattle, WA

Leggett WC, DeBlois E (1994) Recruitment in marine fishes: Is it regulated by starvation and predation in the egg and larval stages. Neth J Sea Res 32:119-134

Leggett WC, Frank KT (2008) Paradigms in fisheries oceanography. Oceanogr Mar Biol Annu Rev 46:331-364

Lemberget T, McCormick MI (2009) Replenishment success linked to fluctuating asymmetry in larval fish. Oecologia 159:83-93

Maxwell BE (1956) Hydrobiological observations for Wellington Harbour. Trans R Soc NZ 88:493-503

McCormick MI, Molony BW (1995) Influence of water temperature during the larval stage on size, age and body condition of a tropical reef fish at settlement. Mar Ecol Prog Ser 118:59-68

McDermott CJ (2005) Understanding patterns of habitat use in reef fish: implications of ontogenetic shifts in habitat-

Editorial responsibility: Nicholas Tolimieri, Seattle, Washington, USA use for population demography. MSc Thesis, Victoria University of Wellington

McDermott CJ, Shima JS (2006) Ontogenetic shifts in microhabitat preference of the temperate reef fish Forsterygion lapillum: implications for population limitation. Mar Ecol Prog Ser 320:259-266

> Meekan MG, Carleton JH, McKinnon AD, Flynn K, Furnas M (2003) What determines the growth of tropical reef fish larvae in the plankton: food or temperature? Mar Ecol Prog Ser 256:193-204

Phillips NE (2004) Variable timing of larval food has consequences for early juvenile performance in a marine mussel. Ecology 85:2341-2346

Phillips NE, Hutchison E (2008) Grazer effects on algal assemblages and mussel recruitment in two different mid-intertidal communities in the Cook Strait, New Zealand. NZ J Mar Freshw Res 42:297-306

SAS Institute Inc (1999) SAS/STAT User's guide, Version 8. SAS Institute, Cary, NC

Searcy SP, Sponaugle S (2000) Variable larval growth in a coral reef fish. Mar Ecol Prog Ser 206:213-226

> Shima JS (1999) Variability in relative importance of determinants of reef fish recruitment. Ecol Lett 2:304-310

Shima JS, Findlay AM (2002) Pelagic larval growth rate impacts benthic settlement and survival of a temperate reef fish. Mar Ecol Prog Ser 235:303-309

> Shima JS, Osenberg CW (2003) Cryptic density dependence: effects of spatio-temporal covariation between density and site quality in reef fish. Ecology 84:46-52

Shima JS, Swearer SE (2009) Larval quality is shaped by matrix effects: implications for connectivity in a marine metapopulation. Ecology 90:1255-1267

Sinclair M (1988) Marine populations: an essay on population regulation and speciation. University of Washington Press, Seattle, WA

Sponaugle S, Grorud-Colvert K, Pinkard D (2006) Temperature-mediated variation in early life history traits and recruitment success of the coral reef fish Thalassoma bifasciatum in the Florida Keys. Mar Ecol Prog Ser 308: $1-15$

Swearer S, Caselle J, Lea DW, Warner RR (1999) Larval retention and recruitment in an island population of a coral reef fish. Nature 402:799-802

Swearer SE, Shima JS, Helberg ME, Thorrold SR and others (2002) Evidence of self-recruitment in demersal marine populations. Bull Mar Sci 70:251-271

Vallès H, Hunte W, Kramer DL (2009) Variable temporal relationships between environment and recruitment in coral reef fishes. Mar Ecol Prog Ser 379:225-240

Wellenreuther M, Barrett PT, Clements KD (2007) Ecological diversification in habitat use by subtidal triplefin fishes (Tripterygiidae). Mar Ecol Prog Ser 330:235-246

Wilson DT, Meekan MG (2001) Environmental influences on patterns of larval replenishment in coral reef fishes. Mar Ecol Prog Ser 222:197-208

Wilson DT, Meekan MG (2002) Growth-related advantages for survival to the point of replenishment in the coral reef fish Stegastes partitus (Pomacentridae). Mar Ecol Prog Ser 231:247-260

Submitted: February 12, 2009; Accepted: September 3, 2009

Proofs received from author(s): November 6, 2009 